\title{
La huella de Quintana en la literatura hispanoamericana
}

$\mathrm{F}_{\mathrm{L}}^{\mathrm{L}}$ ojo avizor de don Marcelino Menéndez Pelayo observó L la relación de escuela que existe entre Quintana, Olmedo y otros poetas de la época neoclásica. En su Historia de la poesía hispanoamericana escribe: "Con decir que Olmedo es el Quintana americano, todo español, aun sin haber leído los versos del vate del Guayas, puede formarse cabal idea de sus perfecciones y también de sus defectos". ${ }^{1}$ Adelantándose sabiamente a la crítica sectaria de nuestros días, al gusto exclusivo, dice él, Menéndez Pelayo se apresura a colocar la poesía de Quintana y de Olmedo en su propio marco temporal: "Y el arte lírico de Quintana, de Gallego y de Olmedo, si en algo $\mathrm{y}$ aun en mucho es eternamente admirable, en algo y en mucho también está ligado a condiciones de tiempo y de lugar, a tradiciones de estilo, a hábitos de escuela, que subjetivamente puede agradar más o menos, pero cuya clave sólo puede encontrarse en el desinteresado estudio de la historia literaria, que es la más eficaz medicina contra las prevenciones de todo gusto exclusivo"."2

Al definir conceptos vagos o ambiguos Menéndez Pelayo es clarísimo: "Píndaro americano se ha llamado a Olmedo, como Píndaro español a Quintana", escribe, ${ }^{3}$ y agrega que Quintana fue pindárico en la substancia ya que no en el modo,

1 M. Menéndez Pelayo, Historia de la Poesia Hispanoamericana (Santander, MCMXLVIII) T. II, p. 30.

2 Ibid., págs. 30-31.

3 Ibid., p. 32. 
dados los cambios de ambiente y de tiempo, y que Olmedo fue pindárico de la misma manera.

Menéndez Pelayo limita su comentario de las semejanzas a La Victoria de Junín y señala como fuente de su última parte el poema de Quintana $A$ la paz de 1795. Quintana exhorta a la diosa de la paz con estas palabras:
En esto ioh diosa! emplea
tu protección sagrada;
tú fecundas el mundo y le sostienes,
tú le das ornamento y se hermosea.
Bajo la sombra de tu augusto velo
las artes viven en concierto amigo,
y seguro contigo,
el genio extiende su brillante vuelo.
A ti en los templos el incienso humea,
a ti las musas su divino acento
sonoramente envían,
$y$ en cuanto el mar rodea,
en cuanto ilustra el sol y gira el viento,
de ti sola su bien los pueblos fían. ${ }^{4}$

Y Olmedo al sol, en forma similar:

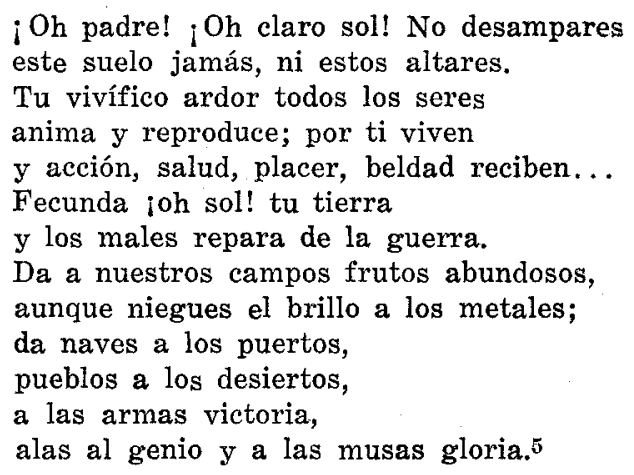

El gran crítico español pasa luego a analizar el americanismo de Olmedo, sus diatribas contra los conquistadores y lo que él llama su "filantropía sentimental" y encuentra el origen de todo esto en el primer verso de la Oda a la vacuna:

4 Ibid., págs. 37, 38.

5 Ibid., p. 38 . 
¿Virgen del mundo, América inocente!

Hay que notar que Menéndez Pelayo cita sólo un verso de aquella estrofa lapidaria en que Quintana se duele del martirio de América; la estrofa entera es digna de mención:

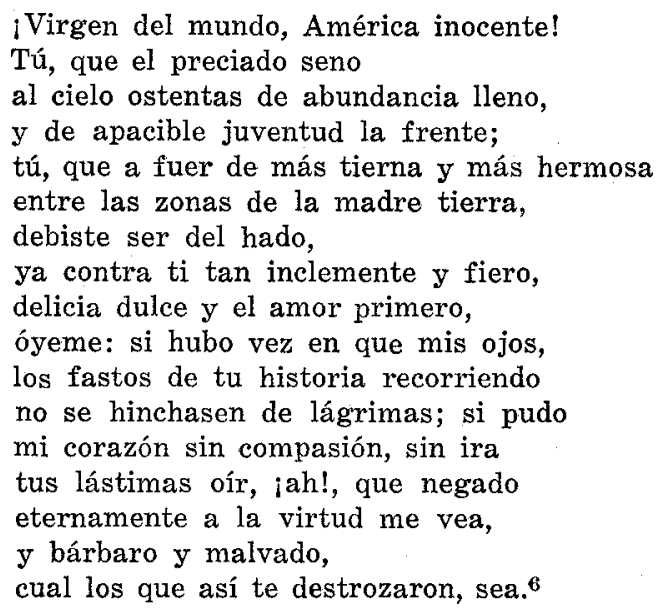

Esta estrofa seguramente ha inspirado muchos versos de Olmedo, como los que escuchamos de boca del inca Huaina Capac:

Un insolente $\mathrm{y}$ vil aventurero $\mathrm{y}$ un iracundo sacerdote fueron de un poderoso rey los asesinos. 7

¿Guerra al usurpador! ¿Qué le debemos?

¿Luces, costumbres, religión o leyes? ¡Si ellos fueron estúpidos, viciosos, feroces, y por fin supersticiosos!s

Por haber cantado a una España libre, y por extensión cordial, a una América libre, algunos - y ya sabemos quiénes-acusaron a Quintana de haber conspirado a la indepen-

6 Quintana, Poesías (Madrid, 1927), págs. 74 y 75.

7 Olmedo, Poesías (París, 1896), p. 64.

8 Ibid., p. 65. 
dencia de América. Su corazón de poeta era demasiado grande para limitar en un círculo geográfico su concepto de patriotismo. El fustigador de tiranos, el cantor de Padilla, se hermana con el cantor de Bolívar; ambos ensalzan a los héroes y alzan una ronca voz de metal para castigar a los déspotas. Trafalgar y Junín son dos acontecimientos históricos; el genio de dos hombres sopla un viento heroico sobre estos hechos, la voluntad de dos hombres libres los eterniza en ritmo y en metáfora. Aunque Quintana no hubiera sido un gran poeta, por su negra ira frente a un Napoleón o a un Felipe Segundo sería digno de la corona de laurel, como lo sería también Olmedo al sonar su clarín, deslumbrado por las hazañas de Bolívar.

Casi todos los críticos que han escrito sobre estos poetas han observado la influencia de Quintana sobre Olmedo. Miguel Antonio Caro afirma rotundamente: "Olmedo es de la escuela de Quintana y esta escuela pertenece a la nobleza de la sangre". ${ }^{9}$ Comparten este juicio Miguel Luis Amunátegui, Manuel Cañete y otros críticos mayores de la época, y hasta nuestros días parece término de obligada comparación la poesía de estos dos poetas. ${ }^{10}$ Quintana es tradicionalmente el cantor del progreso, de la libertad y de la patria. Cada uno de estos temas podría ser ilustrado con un poema mayor como $A$ la imprenta, $A$ Juan de Padilla, A España después de la revolución de marzo. La idea de progreso es también constante en Olmedo:

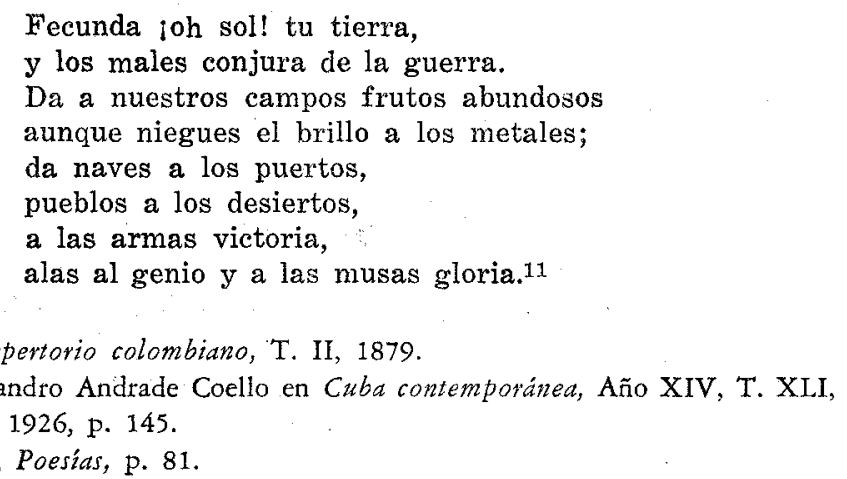


como lo son también las ideas de libertad y patria. En efecto, todo su Canto a Bolívar no es más que la exaltación de estos sentimientos.

Las similitudes de forma, de estilo, entre los dos poetas, son múltiples. Su estudio - ingxato para mí- sería nada más que trazar la trayectoria del neoclasicismo en la América hispana.

Entre José María de Heredia y Quintana hay una diferencia fundamental: Quintana es un poeta cerebral, filosófico, grandilocuente, civil; Heredia es un poeta eminentemente lírico y aun sentimental; Quintana es por escuela y por temperamento poeta neoclásico, Heredia es por temperamento un romántico y por escuela un poeta de transición. Puede observarse que en ciertos temas de grandiosas perspectivas los dos poetas se aproximan en expresión, por ejemplo, al cantar a la libertad, a la patria, al mar, al sol, al Niágara, se aproximan de tal modo que resultan idénticos. Semejanza significa aquí influencia, pues el poeta cubano es, sin duda alguna, discípulo del español. Este vasallaje intelectual lo reconoció Heredia al empezar su oda España libre (1820) con este verso de Quintana: "antes la muerte / que consentir jamás ningún tirano", como también al invocar en el poema el nombre del maestro:

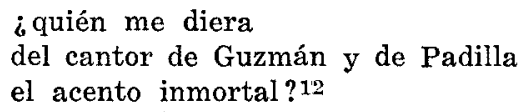

La estructura de este poema es similar a la de la Oda a España después de la revolución de marzo (1808). Quintana empieza su canto con el recuerdo nostálgico de la grandeza pasada de su patria:

¿Qué era, decidme, la nación que un día reina del mundo proclamó el destino, la que a todas las zonas extendía

12 Heredia, Poesias líricas (Paris: Garnier, 1893), págs, 278.279. 


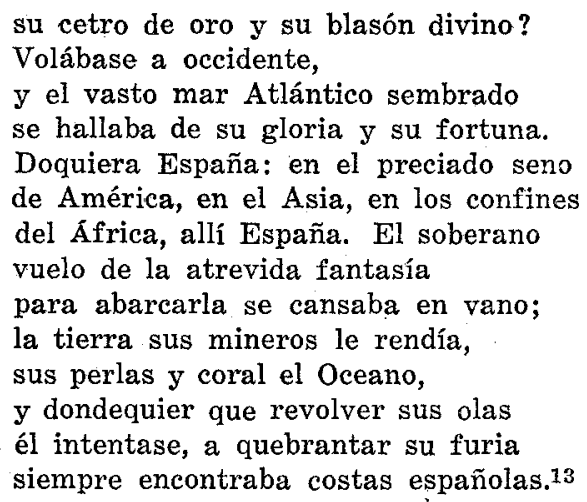

Heredia hace las mismas preguntas acerca del pasado heroico de España:

\author{
¿Eres la misma acaso que algún día \\ tu nombre excelso en alas de tu gloria \\ de polo a polo resonar hiciste? \\ ¿La que tras sí arrastrara la victoria? \\ ¿La que a tus leyes fuertes sometiste \\ al árabe feroz, al italiano, \\ de Lusitania a los valientes hijos, \\ al bátavo, al francés, al otomano, \\ de la Europa terror, al orbe asombro? \\ ¿ (La) ${ }^{14}$ que juzgando del orbe conocido \\ estrecho campo a tan excelsa gloria, \\ lanzaste audaz al piélago profundo \\ a tus hijos heroicos y con ellos \\ buscaste a tus victorias nuevo mundo?15
}

Heredia sigue en este poema el mismo orden de conquistas, victorias y destrucciones que hallamos en el canto a Juan de Padilla de Quintana:

\author{
Indignamente hollada \\ gimió la dulce Italia, arder el Sena \\ en discordias se vio, la Africa esclava,
}

13 Quintana, Poesias, p. 241.

14 Este verso es incorrecto. Es probable que Heredia escribiera: "que juzgando del orbe conocido".

15 Heredia, Poesias líricas, p. 273. 
el bátavo industrioso

al hierro dado y devorante fuego. ${ }^{16}$

Quintana se duele del presente vergonzoso de su patria:

Ora en el cieno del oprobio hundida, abandonada a la insolencia ajena, como esclava en mercado, ya aguardaba la ruda argolla y la servil cadena. ${ }^{1 \tau}$

con la misma lastimosa voz que usa el cubano:

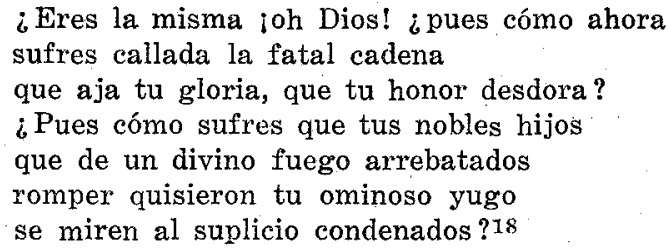

Cuando Heredia encuentra en Quintana el estremecimiento sublime frente a un espectáculo grandioso de la naturaleza le rinde su voluntad de estilo en entrega filial. Frente al mar Quintana pide calma para ofrendar su admiración; su fantasía se eleva a la cima de las pirámides, llega hasta el Olimpo y a la cumbre del Etna, pero nada igual al delirio de contemplar el mar. Tanta majestad le inspira terror y admiración; su mente le sigue por la extensión del planeta y desfallece ante su inmensidad; recuerda los efectos de la tempestad en los bosques y en las mieses que, aunque terribles, no pueden compararse a este fiero hervir del mar. El huracán a veces acompaña la fiereza del mar iinvadirá su furia a la tierra sepultando a los hombres? El hombre, osadamente, trata de domeñar al mar con sus barcos, descubre nuevos mundos, une la tierra y la enriquece, pero luego su codicia convierte esta unión y esta riqueza en violencia y en guerra. El poeta pide al mar que destruya esas naves de guerra. ${ }^{19}$

18 Quintana, Poesías, p. 72.

17 Ibid., p. 241.

18 Heredia, Poesias linicas, p. 273.

10 Quintana, Poesias, p. 149. 
Notamos en el lirismo de Quintana el triunfo del pensamiento filosófico sobre el sentimiento estético. En tanto, Heredia frente al mar ${ }^{20}$ se deslumbra por los ojos, por los oídos, por la emoción de su destierro. Aun ante el fiero aquilón el espíritu de Heredia se exalta y exclama: "espectáculo espléndido, sublime, de rumor, de frescura y movimiento". ${ }^{21}$ Es probablemente en presencia del Niágara en donde el alma del poeta cubano llega al estado de delirio místico que siente Quintana frente al mar. Aquí la imaginación de ambos poetas se iguala por la intensidad de la experiencia y determina elementos semejantes en el mundo metafórico y musical. Cuando Quintana dice: "Cálmate y sufre que la vista mía por tu inquieta llanura se tienda a su placer", Heredia repite: "Calma tu trueno aterrador, déjame contemplar tu faz serena"; si Quintana exclama: "Que ardió mi fantasía en ansia de admirar, y desdeñando el cerco oscuro y vil que la ceñía tal vez allá volaba do la eterna pirámide se eleva y su alta cima hasta el Olimpo lleva", Heredia recoge el eco y dice: "Yo digno soy de contemplarte, siempre lo común y mezquino desdeñando, ansié por lo terrífico y sublime".

De todos los espectáculos grandiosos de la naturaleza el mar es el mayor para Quintana: "mas nada ioh sacro mar! nada ansié tanto como espaciarme en tu anchuroso seno". Para Heredia no hay nada más sublime que el Niágara: "mas del mar la fiereza en mi alma no produjo la profunda impresión que tu grandeza”. Ante el eterno misterio del mar se pregunta Quintana: “¿Dónde es tu fin? ¿En dónde mis ojos le hallarán?" Y ante el misterio del Niágara se pregunta Heredia: "¿Do tu origen está? ¿Quién fertiliza por tantos siglos tu inexhausta fuente?" Ante la grandeza del mar inquiere Quintana: "¿Te hizo el destino para ceñir y asegurar la tierra, o en brazo aterrador hacerle guerra?" Ante la grandeza del Niágara, Heredia: "¿Qué poderosa mano hace que al recibirte no rebose en la tierra el oceano? Más que la tormenta desatada confunde a Quintana:

20 Heredia, Poesias líricas, p. 266, "Al océano".

21 Ibid., p. 268. 


\author{
este ciego, \\ este hervir vividor, estas oleadas \\ que llegan, huyen, vuelven, \\ sin cansarse jamás: tiembla la arena \\ al golpe azotador, y tú rugiendo \\ revuélveste y sacudes \\ una vez $\mathrm{y}$ otra vez: al ronco estruendo \\ los ecos ensordecen, \\ los escollos más altos se estremecen. ${ }^{22}$
}

\title{
y a Heredia:
}

El alma mía

en vago pensamiento se confunde

al mirar esta férvida corriente, que en vano quiere la turbada vista en su vuelo seguir al borde oscuro del precipicio altísimo: mil olas, cual pensamiento rápidas pasando chocan y se enfurecen, $\mathrm{y}$ otras mil y otras mil ya las alcanzan, $\mathrm{y}$ entre espuma $\mathrm{y}$ fragor desaparecen. ${ }^{23}$

Encontrados pensamientos asaltan la mente del poeta español. Los hombres se han servido del mar como de un campo de batalla:
¿Cómo después tan abundosa fuente de amistad y de unión, tornarse pudo de estragos y violencias perenne manantial? Se alzó insolente la vil codicia, y navegar con ella se vio el odio fatal en los navíos. $¿$ No era bastante, impíos, los vientos escuchar que en torno braman, los escollos temblar, mirar el cielo cubrirse todo de espantosas nubes y arderse en rayos, a los pies hirviendo sentir el mar sañudo, y una tabla sutil ser vuestro escudo; sin que a tan tristes plagas añadieseis también la plaga horrenda

22 Quintana, Poesias, p. 151.

23 Heredia, Poesias líricas, p. 225 , 
de la guerra cruel? Ardiendo en ira ella cruza, ella agita, y atronado el ponto, en sangre enrojecer se mira.24

Exactos son los pensamientos que torturan al bardo cubano:
¡Omnipotente Dios! En otros climas vi monstruos execrables
blasfemando tu nombre sacrosanto, sembrar error y fanatismo impio, los campos inundar con sangre y llanto, de hermanos atizar la infanda guerra, y desolar frenéticos la tierra.
Vilos, y el pecho se inflamó a la vista en grave indignación. 25

Por lo anterior es evidente que al escribir su Canto al Niágara (1824) Heredia tuvo a la vista, o retuvo en la memoria, el poema $A l$ mar (1798), de Quintana.

Andrés Bello es el poeta esencialmente clásico de América. Cantó a la independencia, a la libertad, a la paz y al progreso. En esto se aproxima a Quintana, aunque su ardor patriótico es siempre limitado. Lo alejan, sin embargo, de Quintana su sentimiento entrañable de la naturaleza y su profunda fe de hombre católico; le acercan a él su humanitarismo y su deseo de crear una utopía americana. Al estudiar la poesía de Bello se habla a menudo de poesía científica probablemente por la influencia que ejercieron en él los grandes sabios de fines del siglo xviII, Humboldt, Mutis, Caldas, Jovellanos; en esta definición entraría también Quintana, por sus odas más famosas. $\mathrm{Y}$ es en este aspecto donde encontramos un estrecho parentesco entre los dos poetas. Como muchos otros bardos hispanoamericanos de su tiempo Bello escribió una Oda a la vacuna que forzosamente tenía que ofrecer puntos de semejanza con la conocida silva de Quintana al mismo tema. Sé

34 Quintana, Poesias, p. 154.

25 Heredia, poesias lívicas, p. 227. 
que me aproximo aquí a esa crítica enana que se inspira en las "fuentes"; mi disculpa está en el deseo de encontrar semejanzas temáticas y estilísticas, aunque no hay imitación. En su poema A la vacuna (1806) escribe Quintana:
las madres desde entonces
sus hijos a su seno
sin susto de perderlos estrecharon, y desde entonces la doncella hermosa no tembló que estragase este veneno su tez de nieve y su color de rosa. ${ }^{20}$

Y Bello, en el poema del mismo nombre (1804) :
Ya con seguridad la madre amante la tierna prole aprieta contra el pecho, sin temer que le roben las viruelas de su solicitud el caro objeto; ya la hermosura goza el homenaje que el amor le tributa sin recelo de que el contagio destructor ajando sus atractivos, le arrebate el cetro. ${ }^{27}$

En el terreno de la poesía científica, en que se confunden la agricultura y la poesía, es frecuente la comunión de ideas entre Quintana y Bello. En la Oda a la invención de la imprenta expresa este concepto el español:

\author{
No los aromas del loor se vieron \\ vilmente degradados \\ así en la antigüedad: siempre las aras, \\ de la invención sublime, \\ del genio bienhechor los recibieron. \\ Nace Saturno, y de la madre tierra \\ el seno abriendo con el fuerte arado, \\ el precioso tesoro \\ de vivifica mies descubre al suelo, \\ y grato el canto le remonta al cielo, \\ y Dios le nombre de los siglos de oro. ${ }^{28}$
}

26 Quintana, Poesias, p. 76.

27 Bello, Poesias (Santiago de Chile, 1930), p. 20 ,

28 Quintana, Poesías, p. 214. 
que es el mismo expresado por Bello en su famoso Canto a la agricultura de la zona tórrida:

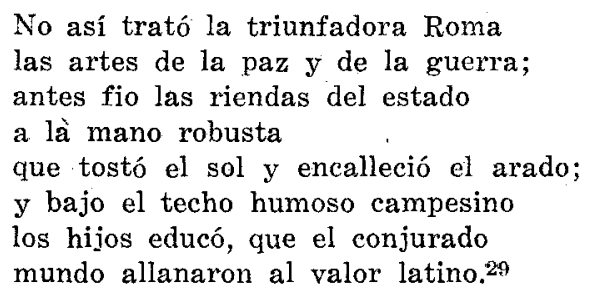

Es probable que Bello nunca sintiera ese temblor divino que va más allá de la poesía lógica, razonada, pero en su perfección formal es digno discípulo del cantor de Padilla.

La huella de Quintana es evidente en estos tres nombres de la lírica hispanoamericana. Yo no sé, ni me interesa saberlo o demostrarlo, si Quintana fue o no un gran poeta. Me basta saber que fue un gran hombre, un poeta amante de la libertad, de la paz y del progreso. $Y$ para terminar, quiero dejar aquí, viva, esta estrofa del poeta, contemporánea, eterna:

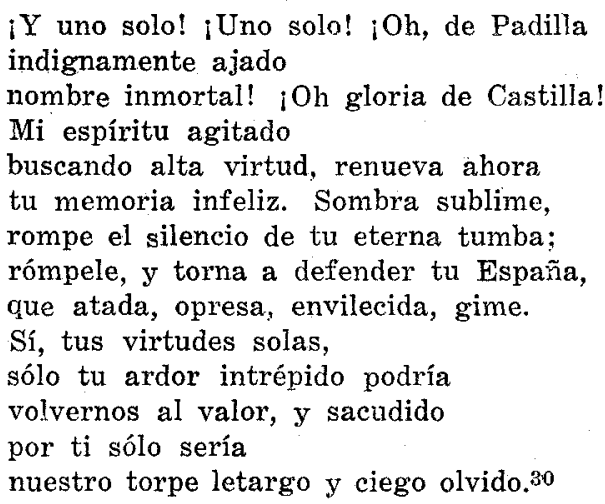

ARTURO TORRES RIOSECO, Universidad de California Berkeley 4, California

29 Bello, 1bid., p. 85.

छ0 Quintana, Ibid., p. 68, 